\title{
Q1 Produção de cenoura em função de doses de potássio e manejos de irrigação
}

Messias Morais Ferreira ${ }^{1}$

César Antônio da Silva²

Sebastião Geraldo Lopes $^{3}$

Fernando Antônio da Silva Lopes ${ }^{4}$

Luís Léssi dos Reis ${ }^{5}$

Pedro Martins Sousa ${ }^{6}$

\section{Resumo}

O objetivo deste trabalho foi avaliar a produção de cenoura, cultivar Brasília, em função de doses de adubação potássica e manejos de irrigação. 0 experimento foi conduzido num Argissolo Vermelho Amarelo, textura média, em Confresa/MT, no período de julho a outubro de 2014 . 0 delineamento experimental foi em blocos ao acaso, com quatro repetições no esquema de parcelas subdivididas 2 × 6 , sendo dois manejos de irrigação por microaspersão (uma vez por dia, de manhã; duas vezes por dia, manhã e tarde) e seis doses de potássio $\left(0,25,50,75,100\right.$ e $\left.125 \mathrm{~kg} \mathrm{ha}^{-1}\right)$, distribuídas em duas partes iguais, aos 20 e 40 dias após a semeadura. A colheita foi feita aos 86 dias após a semeadura. Foram avaliados o número de folhas por planta; a altura da planta (cm); 0 diâmetro de raízes $(\mathrm{cm})$; o comprimento de raízes $(\mathrm{cm})$; as massas de matéria seca de raízes, da parte aérea e total (g planta-1); a produtividade total (t ha-1); a relação das massas de raízes e da parte aérea $\left(\mathrm{g} \mathrm{kg}^{-1}\right.$ ) e o teor de $\mathrm{K}$ foliar $\left(\mathrm{g} \mathrm{kg}^{-1}\right)$. Houve efeito significativo dos manejos de irrigação (I) e das doses de potássio $(\mathrm{K})$ apenas no teor de $\mathrm{K}$ nas folhas e interação de I x K sobre o número de folhas.

Palavras-chave: Daucus carota L. Cloreto de potássio. Manejo.

\section{Introdução}

A cenoura (Daucus carota L.) pertence à família Apiaceae, é originária do Afeganistão, na Ásia Central, e cultivada há cerca de dois mil anos (FILGUEIRA, 2012). A introdução da cenoura no Brasil deu-se no século XVI com a chegada dos portugueses, que trouxeram sementes de várias espécies olerícolas (MADEIRA et al., 2008).

\footnotetext{
1 Instituto Federal de Educação, Ciência e Tecnologia de Mato Grosso (IFMT), Campus Confresa, graduando em Agronomia. Confresa, Mato Grosso, Brasil. messiasanisia@gmail.com. (66) 3464-2600. Avenida Vilmar Fernandes, 300, Setor Santa Luzia, Confresa, Mato Grosso, CEP: 78652-000.

2 Instituto Federal de Educação, Ciência e Tecnologia de Mato Grosso (IFMT), Campus Confresa, professor. Confresa, Mato Grosso, Brasil.cesar.silva@cfs.ifmt.edu.br

3 Instituto Federal de Educação, Ciência e Tecnologia de Mato Grosso (IFMT), Campus Confresa, graduando em Agronomia. Confresa, Mato Grosso, Brasil. tiaodafartura@gmail.com

4 Instituto Federal de Educação, Ciência e Tecnologia de Mato Grosso (IFMT), Campus Confresa, graduando em Agronomia. Confresa, Mato Grosso, Brasil. fernandolopesifmt@gmail.com

5 Instituto Federal de Educação, Ciência e Tecnologia de Mato Grosso (IFMT), Campus Confresa, professor. Confresa, Mato Grosso, Brasil. luis.reis@cfs.ifmt.edu.br

6 Instituto Federal de Educação, Ciência e Tecnologia de Mato Grosso (IFMT), Campus Confresa, professor. Confresa, Mato Grosso, Brasil.pedro.sousa@cfs.ifmt.edu.br
} 
A cenoura é uma raiz tuberosa, considerada a principal hortaliça de raiz em valor econômico e encontra-se entre as dez espécies olerícolas mais cultivadas no Brasil. Em 2011, a produtividade média nacional de cenoura foi de $31,12 \mathrm{t} \mathrm{ha}^{-1}$, com produção total de 780,8 mil toneladas em uma área de aproximadamente 25 mil hectares (VILELA, 2011). O consumo per capita no país, na última

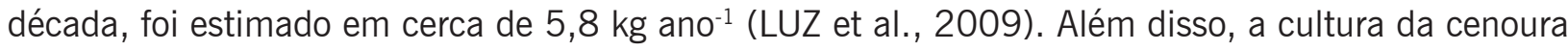
proporciona a geração de empregos e renda em todos os segmentos da cadeia produtiva.

Entre as cultivares de cenoura produzidas no país para o cultivo de primavera-verão, a Brasília tem se destacado, sendo plantada em praticamente todo o território nacional. Brasília Irecê é uma cultivar de cenoura de folhagem robusta, vigorosa e altura de porte médio (25 a $35 \mathrm{~cm}$ ), com raízes cilíndricas, de coloração alaranjada intensa, de até $17 \mathrm{~cm}$ de comprimento e $3,5 \mathrm{~cm}$ de diâmetro, sendo resistente à Alternaria spp. e tolerante ao calor (EMBRAPA, 2007). A cultivar apresenta produtividade média de 35 a $40 \mathrm{t} \mathrm{ha}^{-1}$, conforme as condições edafoclimáticas (RIBEIRO et al., 1999).

A irrigação é uma técnica essencial para o êxito da cultura da cenoura, seja pelo incremento de produtividade, seja pela melhor qualidade de raízes (SILVA et al., 2011), incluindo aumento no teor de caroteno, fibras digestivas e melhoria no sabor (MAROUELLI et al., 2007). No Brasil, a cenoura é irrigada predominantemente pelo sistema por aspersão convencional e pivô central (MAROUELLI et al., 2007), podendo também ser utilizada a microaspersão em pequenas áreas de cultivo.

A cenoura é altamente sensível ao déficit hídrico. 0 desenvolvimento pleno da cultura é obtido quando a umidade do solo é mantida próxima à capacidade de campo durante todo o ciclo. A necessidade de água da cultura da cenoura varia de 350 a 550 mm (MAROUELLI et al., 2007) até 812 mm (SANTOS et al., 2009), dependendo das condições climáticas, duração do ciclo, cultivar e sistema de irrigação. A demanda diária de água aumenta ligeiramente com o crescimento das plantas, sendo máxima no estádio de engrossamento da raiz tuberosa (MAROUELLI et al., 2007). Em termos gerais, déficits de irrigação equivalentes a 20\%,40\% e 60\% da evapotranspiração da cultura reduzem a produtividade de raízes comercializáveis em cerca de 20\%,50\% e 100\%, respectivamente (MAROUELLI et al., 2007).

Da germinação ao término do estádio de plântula (25 a 30 dias), as irrigações devem ser realizadas quando a evapotranspiração da cultura consumir de 40\% a 65\% da água disponível no solo. Do pegamento das raízes à paralisação das irrigações, Shock et al. (2002) recomendam irrigar quando o potencial mátrico estiver entre 15 e 30 kPa para evitar problemas de excesso de água no colo das plantas e de doenças nas raízes.

Na irrigação, não somente a quantidade de água pode influenciar os parâmetros de produção e qualidade de raízes, mas, também, o turno de rega. Segundo Kramer (1969), o estresse hídrico prolongado sofrido pelas plantas pode alterar seu desenvolvimento, modificar a fisiologia, a morfologia e, principalmente, influenciar as reações bioquímicas da planta.

A cultura da cenoura requer solos com ótimas condições físicas (textura, estrutura e permeabilidade). Os solos de textura média, leves, soltos e arejados, que não apresentam obstáculos ao bom desenvolvimento da raiz, são mais favoráveis. A cultura é pouco tolerante à acidez, sendo a faixa de $\mathrm{pH}$ de 5,7 a 6,8 a mais favorável. Recomenda-se que a saturação de bases fique entre $60 \%$ e $70 \%$ e o teor de magnésio do solo seja, no mínimo, de $0,8 \mathrm{cmol}_{\mathrm{c}} \mathrm{dm}^{-3}$ (RIBEIRO et al., 1999).

Quanto à adubação mineral, a recomendação é que essa seja fornecida nas doses de $120 \mathrm{~kg} \mathrm{ha}^{-1}$ de nitrogênio, $320 \mathrm{~kg} \mathrm{ha}^{-1}$ de fósforo e $240 \mathrm{~kg} \mathrm{ha}^{-1}$ de potássio. No plantio é aplicado todo o fósforo recomendado, 30\% do nitrogênio e 40\% do potássio, que devem ser fornecidos no preparo do canteiro, 
juntamente com o adubo orgânico, e incorporados até $15 \mathrm{~cm}$ de profundidade, com antecedência de cinco a dez dias da semeadura. Se o solo for deficiente em boro e/ou em zinco, recomenda-se aplicar de 1,0 a 2,0 $\mathrm{kg} \mathrm{ha}^{-1}$ de B e/ou de 2,0 a 3,0 $\mathrm{kg}^{-1} \mathrm{~h}^{-1}$ de $\mathrm{Zn}$. O restante do nitrogênio (70\%) e do potássio (60\%) devem ser aplicados em duas coberturas, aos 20 e 40 dias após emergência (RIBEIRO et al., 1999).

Pesquisas conduzidas no Brasil revelam que a extração de macronutrientes pela cenoura apresenta a seguinte ordem decrescente: $\mathrm{K}, \mathrm{N}, \mathrm{Ca}, \mathrm{P}, \mathrm{S}$ e Mg. De maneira geral, a adubação de $\mathrm{N}$ e $\mathrm{K}$ é feita, em sua maioria, em cobertura e o fornecimento de Ca é creditado somente à aplicação de calcário e gesso (LUZ et al., 2009).

Experimentalmente, tem-se obtido maiores produtividades da cenoura aplicando o $\mathrm{K}$ na adubação de cobertura (FILGUEIRA, 2012). O K geralmente é o cátion mais abundante nas culturas, encontrando-se nos tecidos, em maior proporção, na forma iônica. Sua absorção se dá pelas raízes, por difusão, contra um gradiente de concentração, tratando-se de um processo predominantemente ativo, endergônico, que necessita de introdução de energia na planta para ocorrer. As duas principais funções do $\mathrm{K}$ na planta estão na abertura e fechamento de estômatos, transpiração e manutenção da fotossíntese. Outras funções influenciadas pelo suprimento de $\mathrm{K}$ incluem a elongação celular, ativação enzimática, síntese de proteínas e transporte de fotoassimilados (YAMADA; ABDALLA, 2004).

Este trabalho foi realizado em razão da existência de poucas informações referentes à aplicação de potássio em cobertura e manejo de irrigação no cultivo de cenoura, no município de Confresa, região nordeste do Mato Grosso, onde a cultura é pouco produzida, sendo necessária a aquisição em outras regiões para atender a demanda do mercado local. Assim, o presente trabalho teve como objetivo avaliar a produção de cenoura em função de doses de adubação potássica e dois manejos de irrigação.

\section{Material e métodos}

O experimento foi conduzido na Chácara Dondé, no município de Confresa/MT, no período de 16 de julho a 11 de outubro de 2014. As coordenadas geográficas da área experimental são latitude 10³9'54,0" sul, longitude 51'34'47,0" oeste e altitude de 215 m. Segundo classificação de Köppen (1948), o tipo de clima predominante na área é o Aw, caracterizado pela existência de três a quatro meses de estiagem, de junho a setembro. O solo apresenta características de um Argissolo Vermelho Amarelo, de textura média (EMBRAPA, 1999).

Foram utilizadas sementes da cultivar Brasília. A semeadura foi realizada em julho de 2014 , manualmente, com a distribuição de aproximadamente $6 \mathrm{~kg}$ de sementes/ha $\left(0,6 \mathrm{~g} \mathrm{~m}^{-2}\right)$, conforme recomendação da EMBRAPA (2000), com distribuição uniforme em sulcos de aproximadamente $2 \mathrm{~cm}$ de profundidade, espaçados em $20 \mathrm{~cm}$ entre si. 0 desbaste foi realizado ao $25^{\circ}$ dia após a semeadura, deixando espaçamento linear de $5 \mathrm{~cm}$ entre plantas.

Foram preparados, manualmente, 16 canteiros de 4,2 m de comprimento e $1 \mathrm{~m}$ de largura. Os canteiros apresentavam espaçamento de $20 \mathrm{~cm}$ entre si, o que possibilitou a realização dos tratos culturais.

O delineamento experimental foi o de blocos ao acaso; consistiu em doze tratamentos, com quatro repetições, em parcelas subdivididas, no esquema $2 \times 6$, sendo dois manejos de irrigação nas parcelas e seis doses de adubação potássica em cobertura nas subparcelas, totalizando 48 unidades experimentais. Cada subparcela apresentava área de 1,2 $\mathrm{m}^{2}$. 
Os manejos consistiram em duas frequências de irrigação: uma vez por dia, de manhã (6h15 - 7h15; duas vezes por dia (6h15 - 7h15 e 17h30 - 18h30). Utilizou-se do sistema de irrigação por microaspersão com emissores de vazão média de $71 \mathrm{~L} \mathrm{~h}^{-1}$, pressão de serviço de aproximadamente $100 \mathrm{kPa}$ e raio de alcance de 2,5 m.

A umidade do solo foi mantida próxima à "capacidade de campo". Para quantificar o tempo de irrigação, foram utilizados seis vasos de pesagem, preenchidos com solo e cultivados com cenoura, os quais eram pesados diariamente para quantificar a evapotranspiração potencial (ETp) da cultura.

Para determinar a umidade na "capacidade de campo", inicialmente colocou-se uma manta de Tecido Não Tecido (TNT) e uma camada de $1 \mathrm{~cm}$ de brita no fundo dos vasos. Em seguida, os vasos foram preenchidos com solo dos canteiros, de forma homogênea e imersos em água até a metade de sua altura para saturação. Após 24 horas, atingida a umidade de saturação, os vasos foram retirados da água e colocados numa bancada, sendo vedada a borda superior para evitar evaporação. Os vasos permaneceram na bancada por aproximadamente 36 horas até drenar todo o excesso de água e atingir a umidade na "capacidade de campo" $\left(\theta_{c c}\right)$, conforme metodologia de Casaroli e Jong van Lier (2008). Os vasos foram pesados, e após obtida a massa de solo na umidade na "capacidade de campo", realizou-se o cultivo.

O solo de um vaso adicional foi colocado para secar em estufa para determinação da umidade na capacidade de campo $\left(\theta_{c c}\right)$, conforme a Eq. 1, obtendo-se a $\theta_{c c}$ de $0,2608 \mathrm{~cm}^{3} \mathrm{~cm}^{-3}$.

$$
\theta_{\mathrm{cc}}=\frac{\mathrm{V}_{\mathrm{a}}}{\mathrm{V}} \quad \therefore \quad \theta_{\mathrm{cc}}=\frac{\mathrm{d}_{\mathrm{a}} \cdot \mathrm{M}_{\mathrm{a}}}{\mathrm{V}}
$$

Em que: $\theta_{c c}$ é a umidade na "capacidade de campo", com base em volume $\left(\mathrm{cm}^{3} \mathrm{~cm}^{-3}\right) ; V_{a}$ é o volume de água $\left(\mathrm{cm}^{3}\right) ; \mathrm{M}_{\mathrm{a}}$ é a massa de água (g) obtida após secagem do solo contido no vaso; $\mathrm{d}_{\mathrm{a}}$ é a densidade da água $\left(1,0 \mathrm{~g} \mathrm{~cm}^{-3}\right)$; $\vee$ é o volume total de solo no vaso $\left(\mathrm{cm}^{3}\right)$.

A lâmina de irrigação aplicada diariamente foi igual à ETp da cenoura, entre duas irrigações consecutivas, determinada pela Eq. (2):

$$
\operatorname{ETp}=\frac{40 \cdot\left(\mathrm{M}_{\theta c c}-\mathrm{M}_{\theta \mathrm{a}}\right)}{\rho_{\mathrm{a}} \cdot \pi \cdot \mathrm{D}^{2}}
$$

Em que: ETp é a evapotranspiração potencial $\left(\mathrm{mm} \mathrm{dia}^{-1}\right) ; \mathrm{M}_{\theta c c}$ é a massa do recipiente + plantas + solo na umidade de "capacidade de campo" (g); $\mathrm{M}_{\theta a}$ é a massa média do vaso + plantas + solo na umidade atual ( $\mathrm{g}$; $\rho_{\mathrm{a}}$ é a massa específica da água $\left(1,0 \mathrm{~g} \mathrm{~cm}^{-3}\right)$; D é o diâmetro da borda do vaso $(\mathrm{cm})$ na altura do nível do solo.

A pesagem diária dos vasos foi realizada por meio de balança eletrônica, com capacidade de 40.000 g e precisão de 5 g, colocada sobre uma bancada em nível. Após a pesagem dos vasos, era realizada a reposição do volume de água perdido por evaporação e transpiração, com auxílio de um recipiente e balança, elevando o solo à "capacidade de campo".

O tempo de irrigação (Ti) foi calculado diariamente, em função da ETp, da vazão dos microaspersores e da área superficial do solo nos vasos, conforme deduzido na Eq. (3):

$$
T i=\frac{\text { Volume }}{\text { Vazão }} \quad \therefore \quad T i=\frac{A_{\text {molhada }} \cdot \frac{E T p}{1000}}{\frac{N \cdot q}{1000 \cdot 60}} \quad \therefore \quad T i=60 \cdot \frac{A_{\text {molhada }} \cdot \text { ETp }}{N \cdot q}
$$

Em que: Ti é o tempo de irrigação (min.); ETp é a evapotranspiração potencial da cultura (mm); $A_{\text {molhada }}$ é a área molhada $\left(\mathrm{m}^{2}\right)$ por todos os microaspersores do canteiro, considerando a sobreposição 
e o alcance além dos canteiros; $N$ é o número de microaspersores da $A_{\text {molhada }}$ q é a vazão média dos microaspersores $\left(\mathrm{L} \mathrm{h}^{-1}\right)$, obtida após ensaio em campo.

As doses de adubação potássica utilizadas foram: 0, 25, 50, 75, 100 e $125 \mathrm{~kg} \mathrm{ha}^{-1}$ de cloreto de potássio, definidas conforme a análise química do solo e recomendações para a cultura (FILGUEI$R A, 2012)$. Os resultados de análise química na camada de $0-20 \mathrm{~cm}$ de profundidade, antes da instalação do experimento foram: $\mathrm{pH}=4,5 ; \mathrm{M} . \mathrm{O}=16 \mathrm{~g} \mathrm{dm}^{-3} ; \mathrm{P}$ (Mehlich) $=1,5 \mathrm{mg} \mathrm{dm}^{-3} ; \mathrm{H}+\mathrm{Al}=46$ $\mathrm{mmol}_{\mathrm{c}} \mathrm{dm}^{-3} ; \mathrm{Ca}=24 \mathrm{mmol}_{\mathrm{c}} \mathrm{dm}^{-3} ; \mathrm{Mg}=8,0 \mathrm{mmol}_{\mathrm{c}} \mathrm{dm}^{-3}$; Sat. Bases $=43,9 \% ; \mathrm{CTC}=82,1 \mathrm{mmol}_{\mathrm{c}}$ $\mathrm{dm}^{-3}$ e $\mathrm{K}=3,2 \mathrm{mmol}_{\mathrm{c}} \mathrm{dm}^{-3}$. Aplicou-se calcário no solo para elevar a saturação de bases a $70 \%$, conforme Ribeiro et al. (1999).

A adubação potássica foi fornecida em duas etapas, sendo $40 \%$ dela aplicada no canteiro e incorporada até $15 \mathrm{~cm}$ de profundidade, sete dias antes da semeadura. Os 60\% restantes foram aplicados em duas adubações de cobertura, aos 20 e 40 dias após a emergência, conforme os tratamentos secundários. 0 fertilizante foi diluído em água e distribuído com um regador nas subparcelas. Também foi aplicada a maior dosagem em seis vasos de pesagem, utilizados na medição da evapotranspiração potencial da cenoura. O nitrogênio, o fósforo e os micronutrientes foram aplicados com antecedência de sete dias à semeadura, sendo distribuída a dose total recomendada.

O controle de plantas invasoras foi realizado manualmente, antes e após a semeadura, conforme necessidade.

A colheita foi realizada aos 86 dias após a semeadura. 0 arranquio foi feito manualmente, evitando danos físicos às raízes, que foram levadas para o laboratório de Bromatologia do IFMT Campus Confresa, onde foram avaliados os seguintes parâmetros biométricos:

a) Número de folhas compostas/planta: fez-se a contagem em oito plantas selecionadas na área útil das subparcelas;

b) Altura de plantas ( $\mathrm{cm}$ ): média das oito plantas da área útil, medindo-se do colo até a extremidade da maior folha;

c) Diâmetro médio de raízes (cm): medido com paquímetro digital na porção mediana das raízes;

d) Comprimento médio das raízes $(\mathrm{cm})$ : mediu-se com uma régua, do colo à extremidade da raiz tuberosa;

e) Massa de matéria seca de raízes (MSR, g planta-1): média das oito plantas selecionadas na área útil;

f) Massa de matéria seca da parte aérea (MSPA, g planta-1 ${ }^{-1}$ : média das oito plantas selecionadas na área útil;

g) Massa de matéria seca total: soma de MSR e MSPA;

h) Produtividade total $\left(\mathrm{kg} \mathrm{ha}^{-1}\right)$;

j) Relação MSR/MSPA;

k) Teor de potássio nas folhas $\left(\mathrm{g} \mathrm{kg}^{-1}\right)$.

Nas análises estatísticas, foi aplicada a análise de variância (ANOVA) pelo teste $\mathrm{F}$ a $5 \%$ de significância, sendo utilizado o software SISVAR (FERREIRA, 2011). Os níveis de adubação potássica foram analisados por meio de equações de regressão.

\section{Resultados e discussão}

Verifica-se que não houve efeito significativo de manejos de irrigação (I) e doses de potássio (K) sobre nenhum parâmetro avaliado, com exceção do teor de $K$ foliar $(p<0,05)$. A interação I x K apenas foi significativa para o número de folhas por planta, a $5 \%$ de probabilidade (Tabela 1 ). 
Tabela 1. Resumo das análises de variância do número de folhas (NF) por planta, altura de planta (AP, $\mathrm{cm}$ ), diâmetro de raízes $(\mathrm{DR}, \mathrm{cm})$, comprimento de raízes $(\mathrm{CR}, \mathrm{cm})$, massa de matéria seca de raízes (MSR, g planta $\left.^{-1}\right)$, da parte aérea (MSPA, g planta $\left.{ }^{-1}\right)$ e total (MST, g planta ${ }^{-1}$ ), relação das massas de raízes e parte aérea (MSR/MSPA, $\mathrm{g} \mathrm{g}^{-1}$ ), produtividade total (PT, t ha-1) e teor de potássio nas folhas $\left(\mathrm{TK}, \mathrm{g} \mathrm{kg}^{-1}\right)$ da cultura da cenoura, em função de manejos de irrigação e níveis de adubação potássica. Confresa - MT, 2014.

\begin{tabular}{|c|c|c|c|c|c|c|c|c|c|c|c|}
\hline \multirow{2}{*}{$\begin{array}{c}\text { Fontes de } \\
\text { variação }\end{array}$} & \multirow{2}{*}{$\mathrm{GL}$} & \multicolumn{10}{|c|}{ Quadrados médios } \\
\hline & & NF & AP & DR & CR & MSR & MSPA & MST & $\begin{array}{l}\text { MSR/ } \\
\text { MSPA }\end{array}$ & PT & TK \\
\hline Bloco & 3 & 1,32 & 181,73 & 0,07 & 6,81 & 13,86 & 9,18 & 44,06 & 0,13 & 19659002 & 194,14 \\
\hline Irrigação (I) & 1 & $\begin{array}{c}3,94 \\
\text { NS }\end{array}$ & $\begin{array}{c}50,02 \\
\text { NS }\end{array}$ & $\begin{array}{c}0,20 \\
\text { NS }\end{array}$ & $\begin{array}{c}9,36 \\
\text { NS }\end{array}$ & $\begin{array}{c}11,70 \\
\text { NS }\end{array}$ & $\begin{array}{c}0,94 \\
\text { NS }\end{array}$ & $\begin{array}{c}6,02 \\
\text { NS }\end{array}$ & $\begin{array}{c}0,47 \\
\text { NS }\end{array}$ & 34454268 NS & $\begin{array}{c}653,79 \\
*\end{array}$ \\
\hline Resíduo 1 & 3 & 1,24 & 16,40 & 0,03 & 1,29 & 2,24 & 1,53 & 5,68 & 0,06 & 77608675 & 21,42 \\
\hline Potássio (K) & 5 & $\begin{array}{c}0,40 \\
\text { NS }\end{array}$ & $\begin{array}{c}23,12 \\
\text { NS }\end{array}$ & $\begin{array}{c}0,86 \\
\text { NS }\end{array}$ & $\begin{array}{c}3,20 \\
N S\end{array}$ & $\begin{array}{c}2,78 \\
\text { NS }\end{array}$ & $\begin{array}{c}1,64 \\
\text { NS }\end{array}$ & $\begin{array}{c}3,30 \\
N S\end{array}$ & $\begin{array}{c}0,23 \\
\text { NS }\end{array}$ & 46115316 NS & $39,22 *$ \\
\hline $\mathrm{I} \times \mathrm{K}$ & 5 & 1,66 * & $\begin{array}{c}3,01 \\
\text { NS }\end{array}$ & $\begin{array}{c}0,01 \\
\text { NS }\end{array}$ & $\begin{array}{c}3,74 \\
\text { NS }\end{array}$ & $\begin{array}{c}2,69 \\
\text { NS }\end{array}$ & $\begin{array}{c}3,95 \\
\text { NS }\end{array}$ & $\begin{array}{c}7,19 \\
\text { NS }\end{array}$ & $\begin{array}{c}0,14 \\
N S\end{array}$ & 20724901 NS & $\begin{array}{c}5,99 \\
\text { NS }\end{array}$ \\
\hline Resíduo 2 & 30 & 0,60 & 41,89 & 0,082 & 4,14 & 3,43 & 3,31 & 7,77 & 0,19 & 77805434 & 13,12 \\
\hline Total & 47 & 0,85 & 43,23 & 0,074 & 4,10 & 4,05 & 3,41 & 9,38 & 0,18 & 0,064 & 40,85 \\
\hline \multicolumn{2}{|c|}{ CV 1 (\%): } & 13,06 & 6,21 & 5,95 & 5,21 & 22,99 & 18,87 & 18,24 & 23,10 & 31,04 & 13,45 \\
\hline \multicolumn{2}{|c|}{ CV 2 (\%): } & 9,09 & 9,93 & 9,26 & 9,34 & 28,43 & 27,75 & 21,34 & 41,34 & 31,07 & 10,53 \\
\hline \multicolumn{2}{|c|}{ Média geral: } & 8,53 & 65,19 & 3,10 & 21,78 & 6,51 & 6,55 & 13,07 & 1,05 & 28385,72 & 34,40 \\
\hline
\end{tabular}

** Significativo a $1 \%$ de probabilidade; * Significativo a $5 \%$ de probabilidade; NS - Não significativo pelo teste F; GL - Grau de liberdade; CV - Coeficiente de variação.

Fonte: Elaboração dos autores

$\mathrm{Na}$ Tabela 2 são apresentadas as médias observadas das características avaliadas em função dos manejos de irrigação. Apenas o teor de $\mathrm{K}$ foliar se diferiu entre os manejos de irrigação, sendo maior quando promoveu irrigação de manhã e à tarde. Esse resultado certamente pode estar associado à menor lixiviação do $\mathrm{K}$ para camadas mais profundas, quando fraciona a irrigação necessária duas vezes ao dia. Verifica-se que, em termos de produção de raízes, é preferível irrigar apenas uma vez por dia (de manhã), pois há menor necessidade de mão de obra para manejar a irrigação. 
Tabela 2. Valores médios do número de folhas (NF) por planta, altura de planta (AP, $\mathrm{cm})$, diâmetro de raízes $(\mathrm{DR}, \mathrm{cm})$, comprimento de raízes $(\mathrm{CR}, \mathrm{cm})$, massa de matéria seca de raízes (MSR, g planta-1 ${ }^{-1}$, da parte aérea (MSPA, g planta-1) e total (MST, g planta-1), relação das massas de raízes e parte aérea (MSR/MSPA, $\mathrm{g} \mathrm{g}^{-1}$ ), produtividade total (PT, t ha-1) e teor de potássio nas folhas (TK, $\mathrm{g} \mathrm{kg}^{-1}$ ) da cultura da cenoura, em função de manejos de irrigação e níveis de adubação potássica. Confresa - MT, 2014.

\begin{tabular}{ccccccccccc}
\hline \multirow{2}{*}{$\begin{array}{c}\text { Manejo de } \\
\text { irrigação }\end{array}$} & NF & AP & DR & CR & MSR & MSPA & MST & $\begin{array}{c}\text { MSR/ } \\
\text { MSPA }\end{array}$ & PT & TK \\
\hline $\begin{array}{c}\text { Uma vez/ } \\
\text { dia }\end{array}$ & $8,82 a$ & $64,16 a$ & $3,16 a$ & $22,21 a$ & $7,00 a$ & $6,41 a$ & $13,42 a$ & $1,15 a$ & $29,23 a$ & $33,30 b$ \\
\hline $\begin{array}{c}\text { Duas vezes/ } \\
\text { dia }\end{array}$ & $8,24 a$ & $66,20 a$ & $3,03 a$ & $21,33 a$ & $6,02 a$ & $6,69 a$ & $12,71 a$ & $0,95 a$ & $27,53 a$ & $42,36 a$ \\
\hline Média: & 8,53 & 65,18 & 3,10 & 21,77 & 6,51 & 6,55 & 13,71 & 1,05 & 28,38 & 37,83 \\
\hline DMS: & 1,05 & 4,99 & 0,22 & 1,51 & 1,59 & 1,45 & 2,48 & 0,32 & 8,67 & 4,25 \\
\hline
\end{tabular}

Médias seguidas pela mesma letra na coluna, não diferem entre si, pelo teste de Tukey, a $5 \%$ de probabilidade. Fonte: Elaboração dos autores.

Os resultados indicam a emissão de folhas da cenoura e dependem do manejo de irrigação adotado e da dose de $\mathrm{K}$, sendo o maior NF contabilizado em plantas irrigadas apenas de manhã e que receberam 50 e $125 \mathrm{~kg} \mathrm{ha}^{-1}$. 0 manejo de irrigação no período da manhã e à tarde proporcionou maiores valores observados de altura de planta, enquanto irrigando apenas de manhã, observaram-se maiores médias de diâmetro de raiz e comprimento de raiz (Figura 1).

Com relação à adubação potássica, não houve diferença significativa entre as doses nos parâmetros avaliados, com exceção do teor de $\mathrm{K}$ nas folhas. A ausência de diferença significativa pode ser atribuída a vários fatores, tais como: o baixo $\mathrm{pH}$ do solo, de 4,5, que torna pouco disponível o $\mathrm{K}$ aplicado; a presença de outros cátions, como $\mathrm{Ca}^{2+}$ e $\mathrm{Mg}^{2+}$, que causam inibição competitiva no processo de absorção do $\mathrm{K}^{+}$; o alto teor de $\mathrm{K}^{+}$já encontrado no solo, em relação às quantidades aplicadas. Mesmo fazendo a calagem, é pouco provável que o pH tenha sido corrigido, pois o calcário foi aplicado em solo seco e não ocorreu nenhuma chuva para que houvesse reação e neutralização da acidez. Segundo Yamada e Abdalla (2004), os fatores que influenciam a absorção de K pelas raízes podem ser externos (concentração de $\mathrm{K}$ na solução, cálcio, sódio, tensão de $\mathrm{O}_{2}$, temperatura, umidade) ou internos (concentração de $\mathrm{K}$ e carboidratos na raiz, características da raiz, como raio, comprimento, crescimento e morfologia), velocidade de absorção de água e variedade. 


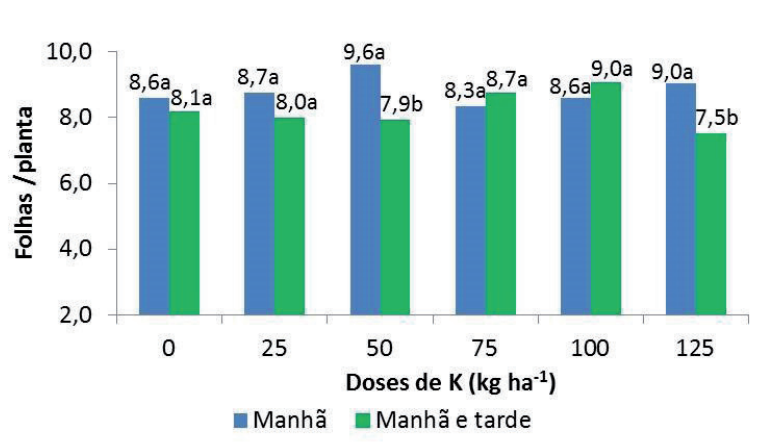

(A)

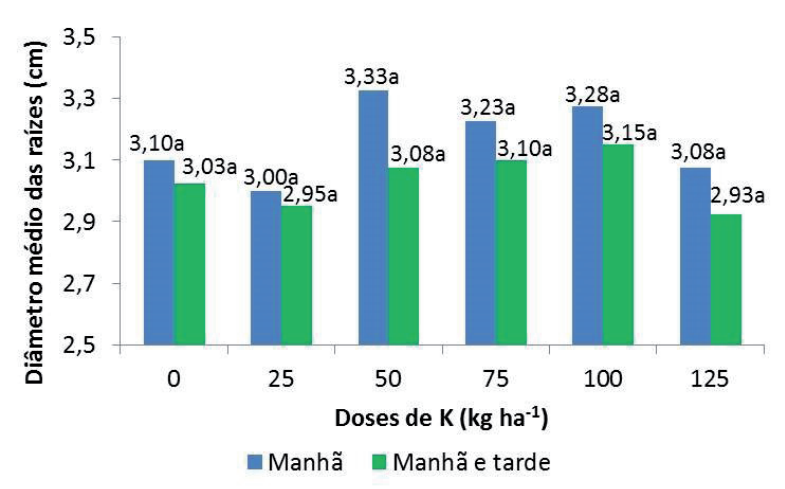

(C)

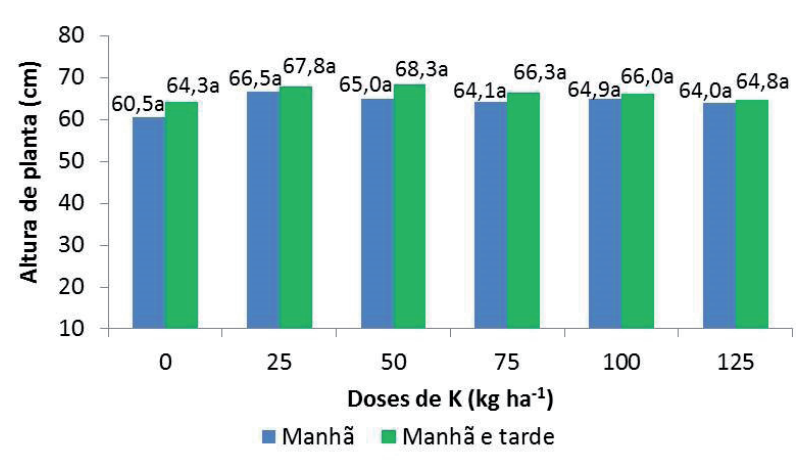

(B)

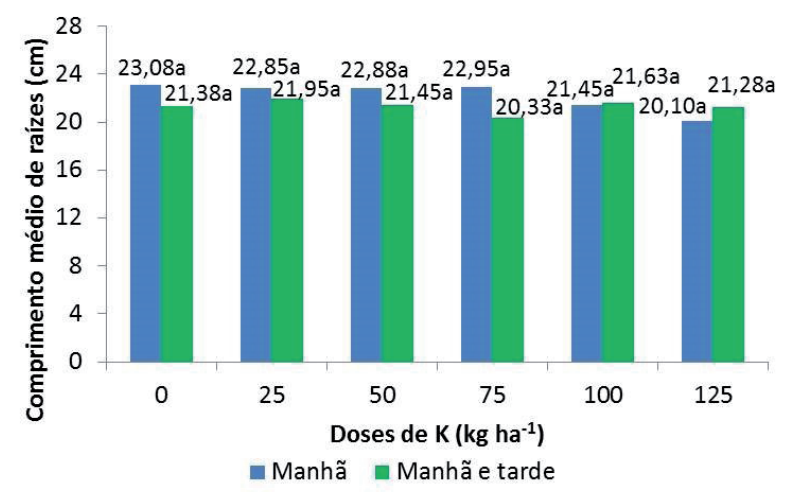

(D)

Figura 1. Número de folhas por planta (A), altura de planta (B), diâmetro de raízes (C) e comprimento de raízes (D) de cenoura em função de doses de K e manejos de irrigação. Confresa - MT, 2014.

Fonte: Elaboração dos autores.

No entanto, a adubação excessiva com potássio pode ocasionar aumento de sais na solução do solo, redução na absorção de outros cátions, principalmente $\mathrm{Ca}^{2+}$ e $\mathrm{Mg}^{2+}$, promovendo redução da produtividade da cultura.

Com relação ao $\mathrm{pH}$, Carolus (1975) relata que a cenoura apresentou ganhos de $25 \%$ em produtividade nos locais com calagem adequada $(\mathrm{pH}=6,5)$, em relação aos locais com calagem inadequada $(\mathrm{pH}=5,4)$. Conforme análises de solo da área experimental, o pH inicial era de 4,5 e, ao término do experimento, de 5,4, estando, portanto, abaixo do recomendado para Daucus carota L.

Com relação à partição da matéria seca, foi observada maior MSPA em relação à MSR apenas nas doses 0 e 50 kg ha-1 de $\mathrm{K}$, quando se irrigou as plantas de manhã, e nas doses de 0, 50, 75 e $100 \mathrm{~kg} \mathrm{ha}^{-1}$, quando a frequência de irrigação foi duas vezes ao dia. Verifica-se que nas dosagens maiores de $\mathrm{K}\left(75,100\right.$ e $\left.125 \mathrm{~kg} \mathrm{ha}^{-1}\right)$ a irrigação uma vez ao dia induz maior produção de MSR do que MSPA (Figura 2). 


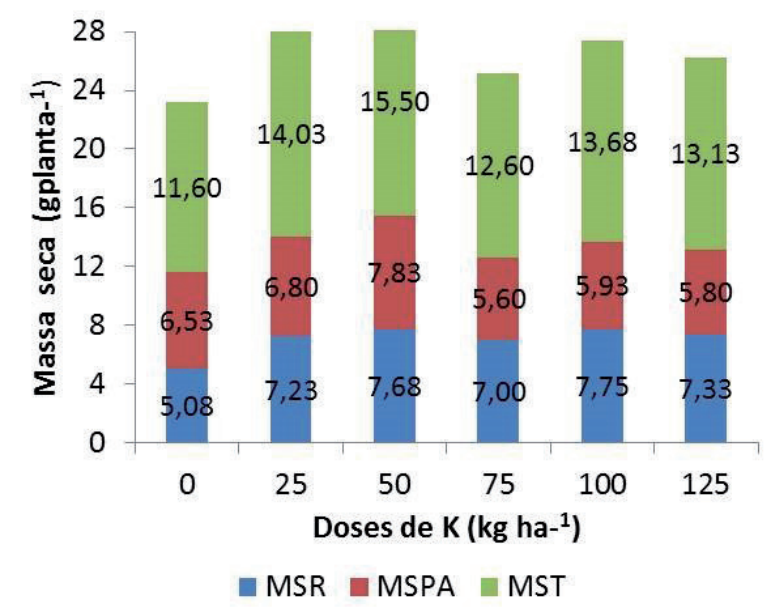

(A)

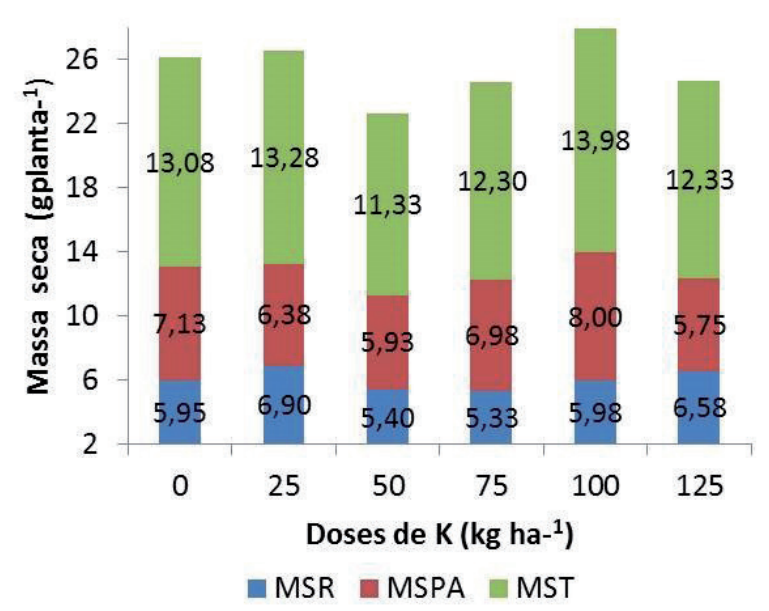

(B)

Figura 2. Massa de matéria seca de raízes (MSR), da parte aérea (MSPA) e total (MST) de cenoura, em função de doses de $\mathrm{K}$ e manejos de irrigação no período de manhã $(A)$ e de manhã e à tarde (B). Confresa - MT, 2014. Fonte: Elaboração dos autores.

Não houve diferença significativa da relação MSR/MSPA entre os manejos de reposição de água, de manhã e de manhã e à tarde. 0 mesmo ocorreu para as doses de $\mathrm{K}$, não havendo diferença significativa (Figura 3).

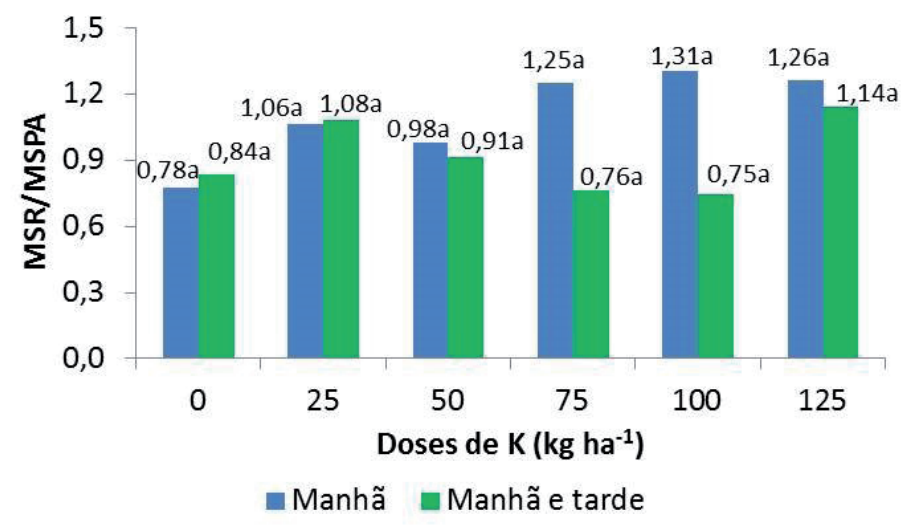

Figura 3. Relação das massas de matéria seca de raízes e da parte aérea, em função de manejos de irrigação e doses de K, Confresa - MT, 2014.

Fonte: Elaboração dos autores

A produtividade total de cenoura também não apresentou diferença significativa em função das doses de $\mathrm{K}$ e dos manejos de irrigação. Com relação ao manejo de manhã, observou-se menor variação na produtividade de raízes em função da adubação potássica. Já no manejo pela manhã e à tarde, houve uma maior oscilação da produtividade em função das doses, conforme é apresentado na Figura 4. 


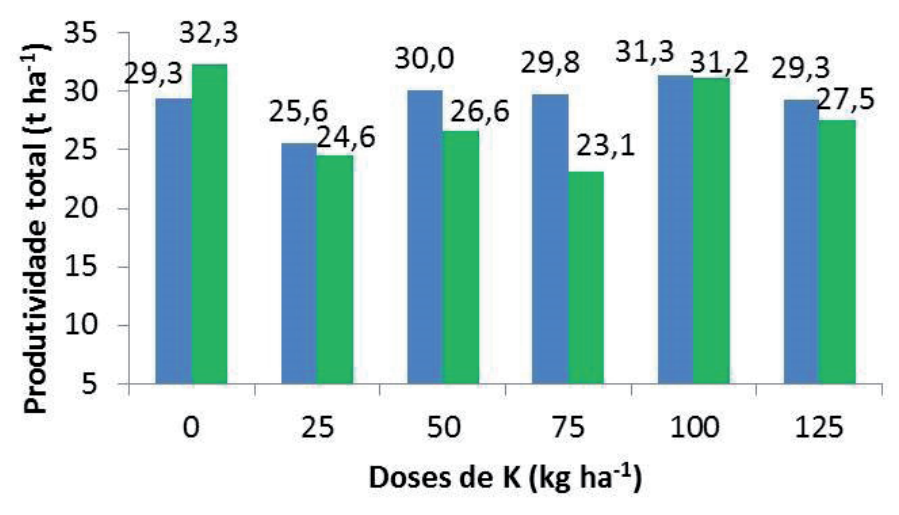

- Manhã Manhã e tarde

Figura 4. Produtividade total da cenoura, em função de manejos de irrigação e doses de K. Confresa - MT, 2014.

Fonte: Elaboração dos autores

As maiores produtividades (32,3 e 31,3 $\mathrm{t} \mathrm{ha}^{-1}$ ) foram obtidas nas doses de 0 e $100 \mathrm{~kg} \mathrm{ha}^{-1}$ de K, valores esses próximos aos obtidos por Luz et al. (2009). Esses autores concluíram que a produtividade máxima de cenoura $\left(27,5 \mathrm{t} \mathrm{ha}^{-1}\right)$ foi obtida com a aplicação de $229 \mathrm{~kg} \mathrm{ha}^{-1}$ do formulado 20-00-20, ou seja, $\mathrm{N}+\mathrm{K}_{2} \mathrm{O}$ em cobertura, não sendo neste trabalho, isolados os efeitos do $\mathrm{N}$ e do $\mathrm{K}$. Na presente pesquisa, fixou-se a dose de $\mathrm{N}$ em cobertura (90 $\mathrm{kg} \mathrm{ha}^{-1}$ ) e variou-se apenas o K. No entanto, a máxima produtividade foi obtida com doses semelhantes de $\mathrm{K}_{2} \mathrm{O}$, pois $229 \mathrm{~kg}$ desse formulado correspondem a 45,8 kg de $\mathrm{K}_{2} \mathrm{O}$. Segundo Filgueira (2012), poucas olerícolas respondem à aplicação de potássio em cobertura e não existem pesquisas para comprovar a necessidade dessa aplicação. Porém, o potássio é o nutriente que apresenta maior teor tanto nas folhas quanto nas raízes da cenoura (SEDIYAMA et al., 2000).

As propriedades físicas, principalmente textura, estrutura e permeabilidade, e as propriedades químicas e biológicas do solo afetam sensivelmente a produtividade e a qualidade das raízes de cenoura (TRANI et al., 2006). Contudo, segundo a lei de Liebig (RAIJ, 1991; MALAVOLTA et al., 1997), um nutriente faltante pode limitar as raízes a se desenvolverem até um padrão de tamanho, não atingindo o ponto de máximo desenvolvimento. 0 ótimo desenvolvimento de raízes somente é atingido quando há equilíbrio no fornecimento de todos os nutrientes essenciais.

Na variável teor de potássio na folha, observou-se que houve efeito significativo dos manejos de irrigação e das doses de potássio. As plantas absorveram mais K no manejo de irrigação de manhã e à tarde. Na dose de $125 \mathrm{~kg} \mathrm{ha}^{-1}$ de $\mathrm{K}$ obteve-se a maior concentração de potássio nas folhas da cenoura (Figura 5). 


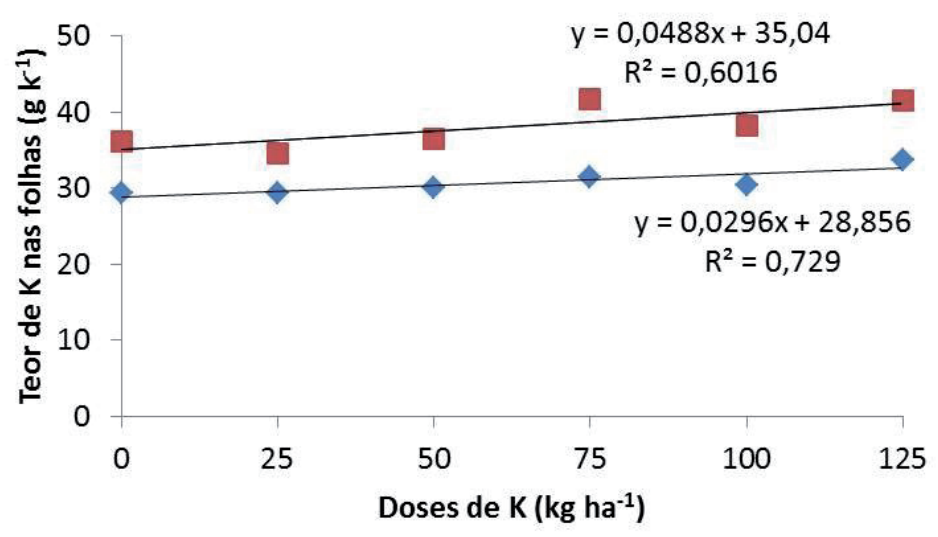

- Manhã $\square$ Manhã e tarde

Figura 5. Teor de potássio na folha da cenoura, em função de manejos de irrigação e doses de K. Confresa MT, 2014.

Fonte: Elaboração dos autores

A demanda diária de água aumenta ligeiramente com o crescimento das plantas, sendo máxima no estádio de engrossamento de raiz. A cenoura é altamente sensível ao déficit hídrico. 0 êxito da cultura é obtido quando a umidade do solo é mantida próxima à capacidade de campo durante todo o ciclo de desenvolvimento das plantas.

Nas condições climáticas do município de Confresa, o consumo médio de água da cultura de cenoura, medido a partir de 30 dias após a semeadura até os 86 dias, quando se realizou a colheita, foi de $1.279,8 \mathrm{~mm}$. A evapotranspiração média da cultura $\left(22,8 \mathrm{~mm}\right.$ dia$\left.^{-1}\right)$ foi superior à citada por Marouelli et al. (2007) e à obtida por Santos et al. (2009), de 812 mm. Isso se deve provavelmente às condições climáticas da região, à utilização de lisímetros de pequenas dimensões (vasos), de menor bordadura, e à época do cultivo, que coincidiu com temperaturas mais elevadas e baixa umidade relativa do ar. Silva et al. (2011) verificaram que a aplicação de uma lâmina total de irrigação de $2.310 \mathrm{~mm}$ ( $180 \%$ da evaporação em tanque "Classe A") proporcionou maior produtividade $\left(67,4\right.$ t ha-1 ${ }^{-1}$ de raízes da cenoura, cultivar Brasília. A maior lâmina de irrigação aplicada no experimento de Silva et al. (2011) não significa que houve maior evapotranspiração da cultura em relação a este trabalho, pois apesar de o ciclo da cultura ter sido mais longo (colheita aos 110 dias), possivelmente uma fração da lâmina de irrigação percolou para horizontes mais profundos do solo.

O manejo da irrigação juntamente com uma adubação equilibrada, que supra a necessidade da cultura, são fundamentais para a obtenção de alta produtividade e raízes de qualidade, sem desperdícios na colheita. Pois, às vezes, há exagero por parte de produtores na aplicação de fertilizantes, tanto no plantio quanto em cobertura. A produtividade média total de cenoura, de 28,3 t ha-1 , está dentro da média nacional que, segundo Marouelli et al. (2007), é de 29 t ha-1, podendo, entretanto, atingir índices entre 50 e $60 \mathrm{t} \mathrm{ha}^{-1}$ em cultivos mais tecnificados.

\section{Conclusões}

Tanto os manejos de irrigação quanto as doses de potássio não apresentam significância nas características biométricas e produção da cenoura.

A irrigação duas vezes ao dia (manhã e tarde) na cultura da cenoura proporciona maior absorção e maior teor de $\mathrm{K}$ foliar em relação à irrigação apenas de manhã. 


\title{
Carrot production in function to potassium levels and irrigation managements
}

\begin{abstract}
The aim of this study was to evaluate the production of carrot from cultivar Brasilia, submitted to potassium fertilization levels and irrigation managements. The experiment was carried out in a Red Yellow Argisol medium texture, in Confresa, Mato Grosso, Brazil, from July to October 2014. The experimental design was in randomized blocks, with four replications in split plots $2 \times 6$, with two micro sprinkler irrigation managements (once daily in the morning, and twice a day, morning and afternoon) and six potassium levels $\left(0,25,50,75,100\right.$ and $\left.125 \mathrm{~kg} \mathrm{ha}^{-1}\right)$ applied to two equal parts at 20 and 40 days after the sowing. Plants were harvested at 86 days after the sowing. The number of leaves per plant; plant height $(\mathrm{cm})$; root diameter $(\mathrm{cm})$; root length $(\mathrm{cm})$; the dry matter mass of roots, from aerial and total part ( $\left.\mathrm{g} \mathrm{plant}^{-1}\right)$, total productivity $\left(\mathrm{t} \mathrm{ha}^{-1}\right)$, the ratio of the dry matter masses of roots and aerial part and $\mathrm{K}$ leaf content $\left(\mathrm{g} \mathrm{kg}^{-1}\right)$ were evaluated. There was a significant effect of irrigation managements and $\mathrm{K}$ levels only on $\mathrm{K}$ content in the leaves and significant interaction $\mathrm{I} \times \mathrm{K}$ on the leaves number.
\end{abstract}

Keywords: Daucus carota L. Potassium chloride. Management.

\section{Referências}

CAROLUS, R. Calcium relationships in vegetable nutrition and quality. Comunications in Soil Science and Plant Analysis, New York, v. 6, p. 285-298, 1975.

CASAROLI, D.; JONG VAN LIER, Q. de. Critérios para a determinação da capacidade de vaso. Revista Brasileira de Ciência do Solo, Viçosa, v. 32, n. 1, p. 59-66, 2008.

EMBRAPA. Centro Nacional de Pesquisa de Solos. A nova classificação brasileira de solos. 1999. 1. ed. Disponível em: < http://ainfo.cnptia.embrapa.br/digital/bitstream/item/19350/1/Jacomine.pdf> . Acesso em: 16 jul. 2013.

EMBRAPA. Cultivo da cenoura (Daucus carota L.): cenoura para verão. EMBRAPA Hortaliças, Brasília, 2007. Disponível em: <http://www.cnph.embrapa.br/cultivares/cenbsb.htm>. Acesso em: 30 ago. 2013.

EMBRAPA. Cultivo da cenoura (Daucus carota L.): EMBRAPA Hortaliças, Brasília, 2000. Disponível em: <http://www.cnph.embrapa.br/paginas/sistemas_producao/cultivo_da_cenoura/plantio.htm>. Acesso em: 02 dez. 2014.

FERREIRA, D. F. Análises estatísticas por meio do Sisvar para Windows versão 4.0. In: REUNIÃO ANUAL DA REGIÃO BRASILEIRA DA SOCIEDADE INTERNACIONAL DE BIOMETRIA, 45, 2000, São Carlos, SP. Anais... São Carlos: UFSCar, 2000. p. 255-258.

FERREIRA, D. F. Sisvar: a computer statistical analysis system. Ciência e Agrotecnologia. v. 35, n. 6, p. 1039-1042, 2011.

FILGUEIRA, F. A. R. Novo manual de olericultura: agrotecnologia moderna na produção e comercialização de hortaliças. 3. ed. Viçosa: UFV, 2012, 309-310p. 
KÖPPEN, W. Climatología: con un estudio de los climas de la tierra. México: Fondo de Cultura Económica, 1948. 479 p.

KRAMER, P. J. Plant and soil water relationship: a modem synthesis. New York: Mc-Graw Hil, 1969. 482 p.

LUZ, J. M. Q.; ZORZAL FILHO, A. Z.; RODRIGUES W. L.; RODRIGUES, C. R.; QUEIROZ, A. A. Adubação de cobertura com nitrogênio, potássio e cálcio na produção comercial de cenoura. Horticultura Brasileira, v. 27, n. 4, p. 543-548, 2009.

MADEIRA, N. R.; REIFSCHNEIDER, F. J. B.; GIORDANO, L. B. Contribuição portuguesa à produção e ao consumo de hortaliças no Brasil: uma revisão histórica. Horticultura Brasileira, v. 26, n. 4, p. 428-432, 2008.

MALAVOLTA, E.; VITTI, G. C.; OLIVEIRA, S. A. de. Avaliação do estado nutricional das plantas: princípios e aplicações. 2. ed., Piracicaba: PATAFÓs, 1997.

MAROUELLI, W. A.; OLIVEIRA, R. A.; SILVA, W. L. C. Irrigação da cultura da cenoura. Circular Técnica 48. Brasília: Embrapa Hortaliças, 2007. 14 p.

RAIJ, B. van. Fertilidade do solo e adubação. Piracicaba: Agronômica Ceres, 1991. 343p.

RIBEIRO A. C; GUIMARÃES P. T. G.; ALVAREZ, V. V. H. Recomendações para o uso de corretivos e fertilizantes em Minas Gerais: 5. Aproximação. Viçosa: UFV, 1999. 359p.

SANTOS, F. X.; MONTENEGRO, A. A. A.; SILVA, J. R.; SOUZA, E. R. Determinação do consumo hídrico da cenoura utilizando lisímetros de drenagem, no agreste pernambucano. Revista Brasileira de Ciências Agrárias, v. 4, n. 3, p. 304-310, 2009.

SEDIYAMA, M. A. N.; VIDIGAL S. M.; PEREIRA P. R. G.; GARCIA, N. C. P.; DELIMA P. C. Produção e composição mineral de cenoura adubada com resíduos orgânicos. Bragantia, Campinas, v. 57, n. 2, p. 379-386, 2000.

SHOCK, C.; FEIBERT, E.; ELDREDGE; E.; SAUNDERS, M.; BUTLER, M.; CAMPBELL, C.; CROWE, F.; SEXTON, P.; KLAUZER, J. Progress report on microirrigation in Oregon. 2002. Disponível em: <http://www.cropinfo.net/W-128/StateReports/2002Reports/20020regon Report.html>. Acesso em: 15 ago. 2013.

SILVA, V. J. da; TEODORO, R. E. F.; CARVALHO, H. de P.; MARTINS, A. D.; LUZ, J. M. Q. Resposta da cenoura à aplicação de diferentes lâminas de irrigação. Bioscience Journal, v. 27, n. 6, p. 954963, 2011.

TRANI PE; MINAMI K; RAIJ B; SAKAI E; MELLO SC; TIVELLI SW. Calagem em cultivos sucessivos de cenoura e alface. Horticultura Brasileira. v. 24, n. 1, p. 59-64. 2006.

VILELA, N. J. Situação das safras de hortaliças no Brasil nos anos 2000-2011. EMBRAPA Hortaliças. 2011. Disponível em: <http://www.cnph.embrapa.br/paginas/hortalicas_em_numeros/producao_hortalicas_brasil_2000_2011.pdf>. Acesso em: 16 set. 2013. 
YAMADA, T.; ABDALLA, S. R. S. Tecnologia para agricultura. Piracicaba: POTAFOS, 2004. 14p. Boletim Técnico, n. 107.

\section{Histórico editorial}

Submetido em: 21/01/2015

Aceito em: 16/03/2015 